\title{
The quest for effective interdisciplinary graduate supervision: \\ A critical narrative analysis
}

Kathryn Hibbert, Lorelei Lingard, Meredith Vanstone, Elizabeth Anne Kinsella, Pam McKenzie, Allan Pitman, \& Tim D. Wilson.

Western University

\begin{abstract}
Interdisciplinarity is a pervasive trend in $21^{\text {st }}$-century knowledge building and innovation. It is predicated on the recognition that creative solutions to the world's increasingly complex problems require the intersection of diverse expertise. Little scholarly attention has been directed towards how the new interdisciplinary (ID) model is influencing the processes and outcomes of graduate research training. In a qualitative study informed by critical narrative analysis and conducted at one institution, we investigate the epistemological, structural, and relational factors that shape ID doctoral research supervision, explore how differing knowledge cultures and values are negotiated in supervisory practices, and consider how established structures and discourses influence the processes and outcomes of these supervisory relationships.
\end{abstract}

\section{Résumé}

$\mathrm{Au} 21^{\mathrm{e}}$ siècle, l'interdisciplinarité (ID) est une tendance répandue en matière de renforcement des connaissances et d'innovation. Cette tendance repose sur la reconnaissance que les solutions créatives aux problèmes de plus en plus complexes du monde nécessitent l'intersection de compétences diverses. Les universités ont porté peu d'attention à la façon dont le nouveau modèle ID influence le processus et les résultats de la formation en recherche pour les cycles supérieurs. Dans une étude qualitative menée dans un établissement 
guidé par l'analyse narrative critique, nous étudions les éléments épistémologiques, structurels et relationnels qui forment la supervision de la recherche doctorale en ID, nous explorons la façon dont les différentes cultures et valeurs des connaissances sont négociées dans les pratiques de surveillance et nous examinons la façon dont les structures et les discours établis influencent les processus et les résultats de ces relations de supervision.

It is easy to forget how mysterious and mighty stories are. They do their work in silence, invisibly. They work with all the internal materials of the mind and self. They become part of you while changing you. Beware the stories you read or tell; subtly, at night, beneath the waters of consciousness, they are altering your world. (Okri, 1995, p. 34)

\section{The Beginning of Our Story}

Interdisciplinarity, a pervasive trend in knowledge building and innovation, is predicated on the recognition that creative solutions to the world's increasingly complex problems require the intersection of diverse expertise. In 2008, the Survey of Earned Doctorates indicated that almost 29\% of American doctorates drew on two or more research fields (Millar \& Dillman, 2010a). The goal of interdisciplinary (ID) work is "to integrate knowledge or modes of thinking in two or more disciplines or established areas of expertise to produce a cognitive advancement... in ways that would have been unlikely through single disciplinary means" (Boix Mansilla \& Duraising, 2007, p. 219). Interdisciplinarity requires knowledge builders who can work interdependently and collaboratively in ways that transcend traditional disciplinary boundaries (Davies \& Devlin, 2010). In higher education, the ID doctoral program has emerged as a popular vehicle for producing this new generation of knowledge builders (Holley, 2013; Millar \& Dillman, 2010a). The growth of ID research at the doctoral level has been supported by funding agencies (SSHRC 2011; NSF 2011; CIHR 2006) and by enthusiasm from faculty and students (Begg \& Vaughn, 2012; Rhoten, 2004; Rhoten \& Parker, 2004). Although both formal ID graduate programs and informal ID training opportunities are proliferating in Canadian universities (Sá, 2006, 2008a, 2008b), little scholarly attention has been directed towards how the new ID model is influencing the processes and outcomes of graduate research training. How are those of us working in ID supervisory contexts faring in our efforts to raise a new generation of ID knowledge builders? The expansion of ID work at the doctoral level has implications for the student-supervisor relationship as well as the processes and outcomes of doctoral research, and requires strategies and support specific to the context of ID research (Lyall \& Meagher, 2012; Parchoma \& Keefer, 2012).

The supervisory relationship is widely acknowledged as a driving force in the socialization and identity formation of graduate students (Lofstrom \& Pyhalto, 2012), yet we know almost nothing about the phenomenon of ID graduate supervision and its ability to effectively produce the next generation of ID researchers and leaders (Schmidt et al., 2012; Spelt et al., 2009; Vanstone et al., 2013). What little we do know suggests that ID graduate training presents new challenges that may be ill-fitted to the disciplinary 
and organizational traditions of doctoral supervision, particularly within traditions such as those in North America, where doctoral students are supervised by a committee of scholars. ID supervisory committees often require cooperation between scholars from paradigmatically incommensurate disciplines. The lack of scholarship in this domain has contributed to a situation in which ID students and supervisors commonly work in isolation, unaware of strategies and best practices to support successful ID research. Without a scholarship of ID supervision to guide our efforts, we cannot monitor practices at the organizational level and measure our progress towards more robust interdisciplinarity in future generations of knowledge builders. We risk wasting time and funding when those working in ID supervisory relationships struggle invisibly (Zhao, 2010). Worse, we risk unintentionally constraining the innovation of those who do successfully graduate to become the next generation of ID knowledge builders.

To investigate the process and impact of ID doctoral research, we decided to learn more about the ID graduate experience from the perspectives of students and their supervisors working within the context of ID supervisory committees at a Canadian university. We wondered: How do interdisciplinary supervisory relationships unfold in this context? How are epistemological and paradigmatic borders negotiated? What structures or discourses support and constrain the practice of interdisciplinary graduate supervision?

As a group of diverse scholars at one university, this research team shares a commitment to improve our ability to work with and for our graduate students. The cautionary epigraph that invited you into this paper is one we have taken very seriously. The aims of narrative inquiry fit with our goals: to identify and share stories of practice so that they may inform and improve teaching and advising (Spector-Mersel, 2010). In this work, we listened to hear what stories underpinned the discourse and activities of ID work, to learn how they may be invisibly shaping our world.

Narrative inquiry emphasizes relationships or collaboration between the researcher and others (Lannamann \& McNamee, 2011; Pinnegar \& Daynes, 2007). As Madeleine Grumet (1988) claims in Bitter Milk, "knowledge evolves in human relationships" (p. xix). This paper describes the process of our work as much as the focus and the findings.

\section{Background}

Despite the expansion of interdisciplinary programs, the practical and theoretical challenges of ID graduate supervision still need to be addressed (Australian Teaching and Learning Council, 2010). While a review of the literature demonstrates a large body of publications on the phenomenon of interdisciplinarity (Aboelela et al., 2006 ) and some attention to graduate supervision (Deuchar, 2008; Grant, 2003, 2005; Halse \& Malfroy, 2010; Lee, 2008; McCallin \& Nayar, 2012; Sambrook, Stewart, \& Roberts, 2008), very little research has attended to interdisciplinary supervision (Vanstone et al., 2013).

The supervisory relationship is the backbone of most graduate programs, and the literature includes numerous examples of faculty development programs for supervisors of graduate students (McCormack \& Pamphilon, 2004). However, beyond an instrumental level, graduate supervision remains a poorly understood phenomenon (Grant, 2003, 2005). This may be due, in part, to the fact that the relationship between supervisor and graduate student has been considered "essentially privatized and personalized," one traditionally conducted behind "closed doors" (Green \& Lee, 1995; McWilliam \& Palmer, 
1995). This last point is particularly significant because, as Petersen (2007) contends, the supervisory relationship is a primary vehicle through which students begin to identify as academics. For those engaged in interdisciplinary scholarship, this process of identity formation may be further complicated by the need to negotiate multiple interdisciplinary identities (Beddoes, Borrego, \& Jesiek, 2011; Boden, Borrego, \& Newswander, 2011; McNair, Newswander, Boden, \& Borrego, 2011).

The recent emergence of ID graduate education programs may further complicate the supervisory relationship. The formation of the "academic self" (Manathunga, 2007) may require a different approach when contending with disciplinary differences (Manathunga, Lant, \& Mellick 2006). The situation is complicated by cross-disciplinary and co-supervision situations (Kiley, 2009), multiple theoretical orientations on supervisory committees (Nisselle \& Duncan, 2008; Taylor \& Beasley, 2005), and disciplinary differences of opinion on the purpose (Franke \& Arvidsson, 2011; Nisselle \& Duncan, 2008), format, and content (Blackmore \& Nesbitt, 2008) of the PhD.

The recent emergence of ID graduate education programs has the potential to further complicate the supervisory relationship (Walker \& Thomson, 2010). ID "education is commonly practiced, [but] a surprisingly small body of theory has accumulated" (Spelt et al., 2009, p. 378). Existing research has been criticized as limited and explorative, with an emphasis on lower-level, programmatic information such as learner satisfaction (Hall \& Weaver, 2001; Spelt et al., 2009).

\section{Theoretical Overview}

This study is located in a qualitative, interpretive paradigm (Denzin, 2001) that seeks to "make the world of lived experience visible to the reader" (p. 34). It is guided by a critical narrative approach that takes as axiomatic the belief that humans individually and collectively construct meaning in their relationships with one another, as situated within various contexts. Narrative thinking structures experiences according to three "commonplaces": temporality, the personal-social dimension, and space. It seeks to understand both the construction and the application of knowledge as situated practice (Bruner, 1996). A critical perspective is particularly appropriate for this study because it emphasizes that meaning is derived from multiple perspectives negotiated with the cultural members of a particular group (Trujillo, 1985; Wenger, 1998), influenced and concerned with issues such as gender, power, and context.

We do not seek to tell the story of ID graduate supervision; rather, a critical narrative approach positions us to organize and explore multiple perspectives, including the interplay between student and supervisor within institutional and sociocultural contexts designed for disciplinary research (Clandinin \& Rosiek, 2007). Critical narrative methods afforded us a means to reflect our findings through a quest narrative rooted in the data, while respecting participants' heightened need for anonymity, given the sensitive nature of the data for student and faculty relationships in progress.

The process of both telling and re-telling stories, situated in their various contexts, and reflecting on the parts and the whole leads to a deeper understanding through "a process of testing, clarifying and deepening our understanding of what is happening in the discourse" (Mishler, 1991, p. 277). Using this approach, we ask: "What are the dominant or meta-narratives of ID graduate supervision (e.g., the overarching stories that are told)? 
What are the 'cover narratives' (e.g., the stories that reflect tellers' interpretations of what should happen)? What are the private narratives (the stories that reflect individual experiences)?” The emerging stories and metaphors articulate and make visible what is, allowing us to critically assess what might be.

An additional theoretical lens orients us to this work. Drawing on Lee and Green's (2009) conceptualization of "supervision-as-pedagogy," we view interdisciplinary supervision "as centrally involving the relationship between a (student) learner, [their] teacher[s], and the knowledge produced through that relationship" (p. 617). Unique in this relationship is the interaction involved among "two or more different disciplines...ranging from simple communication of ideas to the mutual integration of organizing concepts, methodology, procedures, epistemology, terminology, [and] data" (Manathunga, Lant, \& Mellick, 2006, p. 366). Britzman (1991) describes the search for meaning as a fluid construct, one that is "interpretive, constructivist, and critical, moving back and forth between the story, its telling, and the contingencies of perspectival borders" (p. 14). Understanding ID supervision as pedagogic practice (Green, 2005; Holley, 2013) ensures that we attend particularly to the subjectivities and identity formation within this central relationship.

ID graduate student supervision is a complex relationship located at the nexus of the academic and the personal, the available discourses, resources, and texts that govern the institutions in which we teach and learn - and the sometimes intimate, sometimes conflicted relationship between supervisor and supervisee as they negotiate new meaning in what is often uncharted territory.

\section{Method}

[N]arrative... is a way of understanding experience... [through] collaboration between researcher and participants, over time, in a place... and in social interaction with milieu... Narrative inquiry is stories lived and told. (Clandinin \& Connelly, 2000, p. 20)

\section{Stage 1: Identification of ID Doctoral Students and Supervisors}

Our first task was to map interdisciplinary work at the institution. To identify potential student participants, we emailed an online survey to all registered doctoral students. Of the 76 responses, 68 self-identified as working in interdisciplinary ways. From these, we selected those who aligned with the study's definition of interdisciplinarity. To identify potential faculty participants, we analyzed completed theses (2005-2009) to map the disciplinary affiliations of doctoral supervisory committees common in North American contexts. Our initial list of potential faculty participants included those who had repeatedly served on doctoral committees and exams representing three or more disciplines.

\section{Stage 2: Individual Interviews}

After identifying participants through the initial mapping, we conducted semi-structured interviews with a representative sample of nine doctoral students and nine faculty members to gather more in-depth data about their experiences. Guiding questions for both faculty and students were: "How did you become involved in interdisciplinary re- 
search? Tell me about your experiences working (as a graduate student/supervisor) in your graduate program in an ID context. What went well? What could have gone better? How was it different from your disciplinary graduate experiences?” Transcribed interviews were member-checked and revised for clarification or accuracy.

\section{Stage 3: Invitational Meeting and Focus Groups}

Following the individual interviews, the research team began a preliminary analysis to identify the emerging themes or meta-narratives that were represented in the data, and compared these to the meta-narratives reflected in the literature review. We held a focus group in which we checked the emerging "stories" and metaphors with our participants, as it seemed that certain stories were indeed being told (Clandinin \& Connelly, 2000; Creswell, 2008). Seven students and eight faculty members attended to discuss the emerging themes and determine whether we might locate counter-narratives through some innovative methods and focus-group sessions.

We began by organizing the participants into homogeneous focus groups (i.e., groups comprising only students or only faculty). We later split the focus groups into heterogeneous discussion groups to reflect collectively on their focus-group discussions using a jigsaw placemat activity (Figure 1). During the discussion, we displayed a slide show of visual metaphors emerging from the interviews and invited participants to discuss them. We also created a "graffiti wall" (Figure 2), where we posted vivid or representative passages from interview transcripts and invited participants to comment anonymously on them. We gave faculty and students different-coloured pens to identify comments by group.
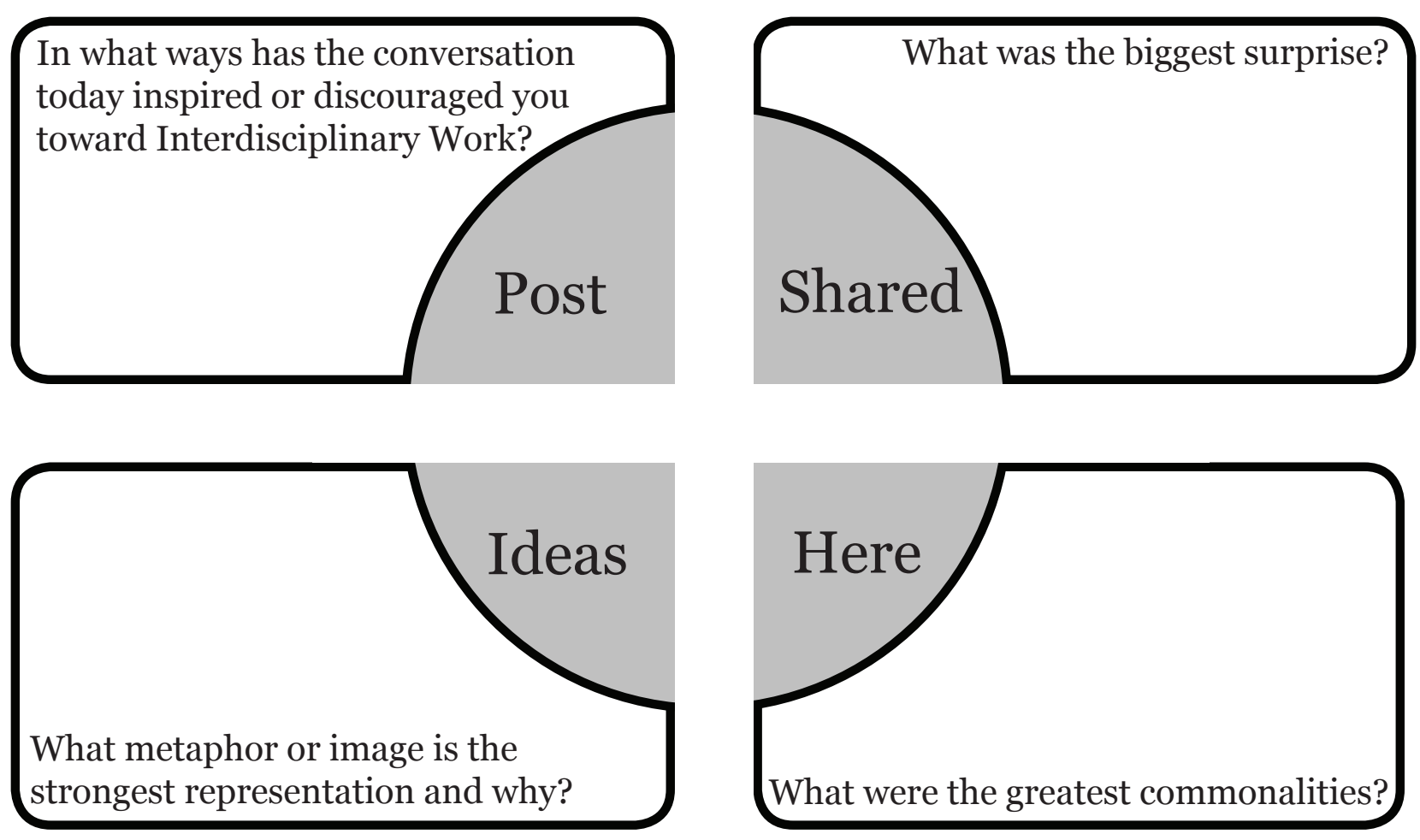

Figure 1. Jigsaw Placemat Activity 


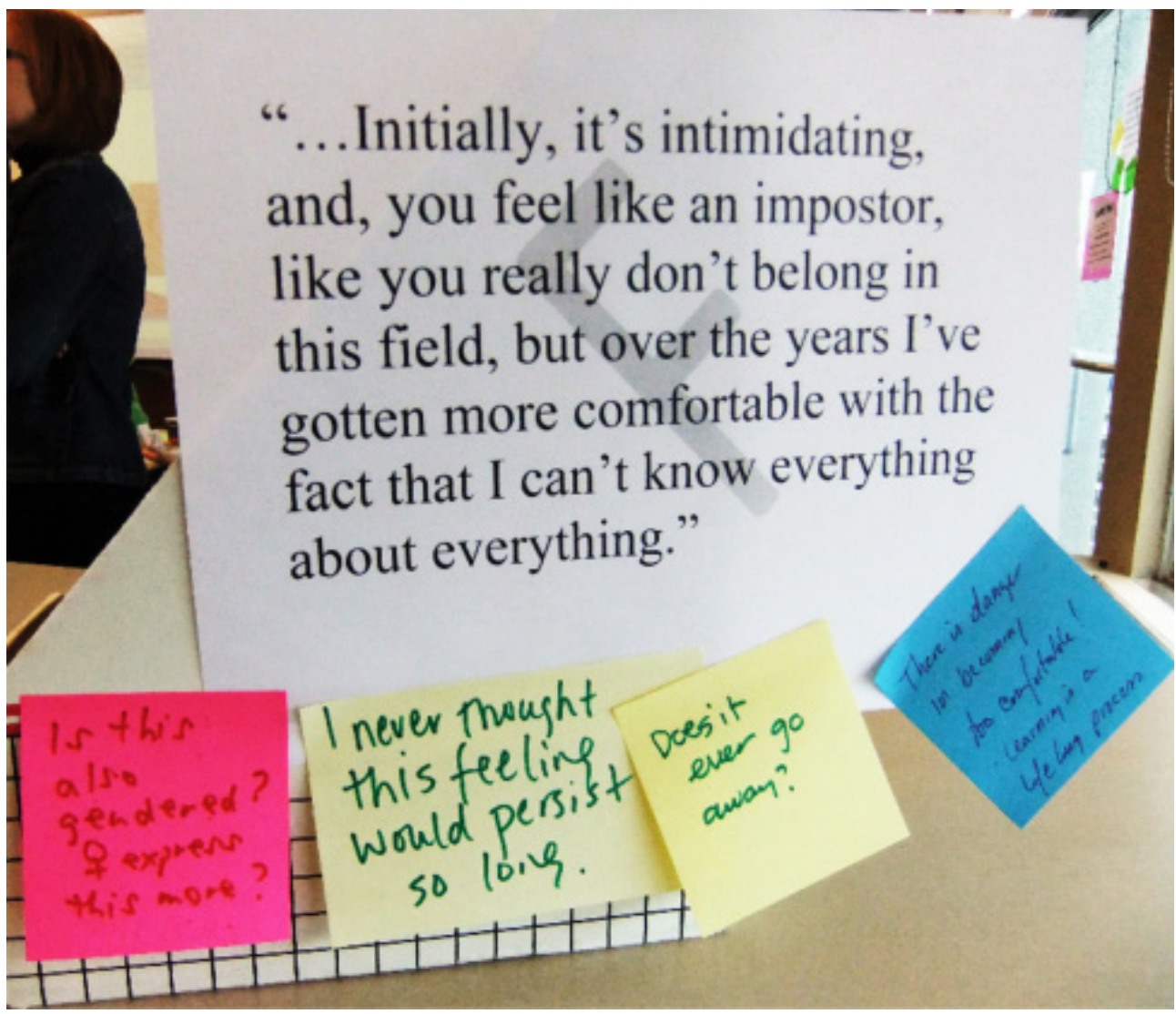

Figure 2. Graffiti Wall

\section{Analysis}

"Re-storying" is a process in which the researcher gathers stories, analyzes them for key elements, and then rewrites the story to place it in a chronological sequence (Creswell, 2008). As a literary form of qualitative research, a narrative approach places a special emphasis on writing (Richardson, 1997). In this study, we were particularly sensitive to the insights shared by participants who were currently in supervisory relationships. The longer we worked with the data, refining and categorizing the stories that were told, the more we could see a particular metaphor emerging. "How we arrange and rearrange the [stories]... in light of our discoveries is a process of testing, clarifying and deepening our understanding of what is happening in the discourse" (Mishler, 1991, p. 277).

Metaphor was a useful way to reduce the data to a core meta-narrative, and narrative devices allowed us to chronicle the events of the meta-narrative. At the same time, we actively sought "counter-narratives" - those stories that do not fit, are "absent," or run counter to the dominant narrative - as a way of challenging interpretation or generating insights related to differences in the socio-cultural context of the "telling." In this study, counter-narratives emerged in both the individual interviews and during the group activities as participants engaged in our methodological innovations (e.g., the jigsaw placemat activity, the graffiti wall, and the responses to visual metaphors). All aspects had to be reflected in the final telling. 


\section{The Emergent Meta-story}

Numerous "stories" emerged from the extensive, rich data set collected. For the purposes of this paper, we focus on the stories told by the doctoral students. Mishler (1995) reminds us:

It is clear that we do not find stories; we make stories. We retell our respondents' accounts through our analytic re-descriptions. We too are storytellers and through our concepts and methods - our research strategies, data samples, transcription procedures, specification of narrative units and structures, and interpretative perspectives - we construct the story and its meaning. In this sense the story is always co-authored... The teller of the tale is also engaged in a retelling. The version we hear or read is shaped both by the context of its telling and the history of earlier retellings. (p. 117-118)

The "meta-story" that emerged from our participants was "re-storied" (Miller \& Salkind, 2002; Mishler, 1995; Spector-Mersel, 2010), loosely organized around the classic Tolkien tale, The Hobbit. Using the narrative structure and characters from this wellknown story allowed us to represent the data through a quest archetype similar to that experienced by ID graduate students, who overwhelmingly described feeling as though they were leading the quest and responsible for navigating a series of challenges. As we present the data in this form, we have chosen to weave together the plot lines in a way that grounds the narrative, leaving room for alternative and creative paths that this story and the stories of our participants may take. It is also important to note that the participants in our narrative do not follow a single path. The data demonstrated that while the destination was shared, the stops along the way and the paths taken could significantly differ.

\section{Narrative 1: The Quest for an Interdisciplinary PhD}

An overview of the quest narrative. In Tolkien's (1937) classic tale, the hobbit and main character, Bilbo Baggins, is persuaded by the wizard Gandalf to join a company of dwarves on a quest for treasure. The group sets off, traveling further from Bilbo's home in Hobbiton than he has ever gone before. Along the way, the group encounters other creatures, some helpful and some harmful. After using every resource they can muster, they meet Smaug, the dragon guarding the treasure in a mountain cave. A great battle ensues, and Bilbo and his team gain the treasure. Eventually, Bilbo returns home and finds that he is not the hobbit he once was, and that life as he knew it in Hobbiton is no longer the same.

The characters. The characters in this narrative include many familiar faces. Bilbo Baggins, the hobbit of the book's title, represents the ID doctoral student, embarking into the unknown in search of treasure guarded by the dragon Smaug (signifying the final examination and defense). Gandalf the wizard represents the supervisor - a wise but enigmatic figure who acts as the conductor of the entire affair. Gandalf introduces Bilbo to a troop of dwarves and elves, who represent the committee members. Initially, no one is sure whether this is the best pairing for the journey: dwarves and hobbits have little in common. Through shared experience, Bilbo and the dwarves learn to work together, benefitting from one another's strengths and accommodating one another's weaknesses. Thorin, leader of the dwarves, is one of the oldest in the group and knows what the trea- 
sure contains and how it came into Smaug's possession. Balin, another dwarf, is the only member of the questing team who has been to the mountain before, and therefore he notices things that the others sometimes miss. Early in their journey, Bilbo and the dwarves meet Elrond, an elf, who provides assistance to the group by interpreting a message on their map that no one else can understand, a message that is instrumental in gaining access to the mountain where the treasure is hidden.

Smaug enters our story at the end of the journey, as he is guarding the treasure. His conversations with Bilbo reveal him to be an arrogant and hateful beast who loves treasure only for the sake of having it. This conversation gives Bilbo the necessary insight into the most efficacious way of defeating Smaug (thus ensuring a successful defence and awarding of a $\mathrm{PhD}$ ).

The setting. Hobbiton, where the journey begins, is a place settled exclusively by (single-disciplined) hobbits. Despite living here for many years, Bilbo has never entirely felt at "home." Indeed, when Bilbo returns to Hobbiton at the end of the journey, he is considered an outsider and does not fully reintegrate into the community, relating only to his adventurous young cousins, to the dismay of their elders. The journey Bilbo experiences takes the group to unknown places that are both exciting and frightening. The group scales the Misty Mountains early in the journey, encountering and outwitting goblins and trolls along the way. Eventually, the group comes to the small town of Carrock, where they are fed and outfitted in preparation for the next challenging and more independent leg of their journey. The final part of the journey, through the Mirkwood forest, is thick, dark, and full of different sorts of evil creatures. After escaping capture, the group reaches their final destination, the Lonely Mountain, containing treasure guarded by the dragon Smaug.

\section{Growing the Metaphor Through the Data}

In this brief sketch of the classic tale, it is easy to find relationships between the questing students, their wise but enigmatic supervisors and supervisory committee members, and challenges they meet along the doctoral journey. These were shared experiences, and many may lightheartedly see their own experiences in this archetypal tale. At this stage of reviewing the data, we become most interested in the stories that challenged the archetype or veered off in new directions. To represent the data as we saw this happening, we employ a technique borrowed from the children's book series "Choose Your Own Adventure $^{\circledR ”}$ (2012). In this series, the story is written from the second-person perspective and the reader takes the protagonist's role. The narrative pauses at crucial plot points to ask the reader to choose among multiple courses of action. Each choice sends the reader to a different page in the book and sets her onto a different plot trajectory. Some trajectories are dead ends, some may loop back to the main path, but only one leads to the desired outcome. This seemed an appropriate choice in that it underscores the importance of developing agency and independence on the doctoral journey, and in this study in particular, it reflected a repeated finding in the data: that ID doctoral students themselves were often leading the quest, navigating challenging terrain, and viewing their committee members for what special "tools" they could provide to ensure successful passage.

We now take you back into our tale, in a way that outlines the varying paths revealed in the data. At each point in the story, we will represent the dominant and counter-narratives. Each student expressed some part of both the dominant and the counter-narratives, 
moving between each experience at different points of their journey. We were very sensitive to protecting the identity of our participants, many of whose supervisory relationships were still in progress. In this paper, then, excerpts that reflect the students' accounts are re-storied; they are thus representations of what was said, using the popular tale as the narrative structure.

\section{Narrative 2: Choose Your Own Adventure Series}

Starting the adventure. You are at home on a beautiful afternoon, smoking your pipe, when a wizard appears and asks whether you'd like to accompany her on an adventure - a quest to find a great treasure. Students who chose their supervisor based on previous disciplinary experiences with that person or shared common interests might say, "Yes, please! I've had previous experiences with you and I know that you and I will work well together. Let's hear about the treasure you have in mind - maybe I can figure out a way to find it. You do have funding for this adventure, right?" Other students, who entered graduate school with a particular ID project in mind, reported choosing a supervisor who could best help them pursue that project: "I've got an idea for my own adventure, but some of your skills might come in handy. Would you like to come along with me? Do you know anyone else who could help us? I'm counting on you to guide me through this adventure, since you are so experienced!"

The majority of the students we interviewed described embarking on an ID project with an idea of the type of research they wanted to do, then looking for faculty who could support their research. They talked about the difficulty of finding a supervisor who had expertise in all areas of the topic; usually, they ended up working with someone who knew one particular part of the project quite well. They would say, "I'm glad you finally showed up! I've been looking all over for someone who could help me on my quest. I have a real interest and excitement about this: I'm working on gathering the right people to help me pursue this. I know mountaineering isn't your main interest, but you've done it before, right? And you used to appraise rubies? I'm looking for someone who can help me steal the treasure guarded by the dragon Smaug. Do you know any dragon lullabies? Or anyone who does?"

Forming the committee. After connecting with a supervisor, students turned their attention to forming a committee that could contribute expertise and perspectives beyond those of their supervisor. Students described different processes and considerations that they went through when choosing committee members. Some expected that the supervisor would recommend the other committee members based on their own connections within the university. These students might say, "Gandalf, could you suggest some people? How about those dwarves I hear you talk about all of the time? They seem like they have an interest in getting the treasure back." Alternatively, some worked in tandem with their supervisor to search out and invite committee members with expertise in research processes rather than in particular topic areas: "Gandalf, let's work together to find a group of people who have expertise in the process of questing. It doesn't matter whether they know anything about dragons, treasure, or mountains." However, the dominant narrative was focused on finding committee members who had expertise in the particular topics of the research, rather than in research processes. Many ID students described having most of the responsibility for finding committee members, with little help from their supervisors: 
I need a group of people who between them are experts on dragons, treasure, and mountains. It would be ideal if they understood mountain-dwelling dragons, or treasure-guarding dragons, but really, as long as all of those bases are covered, I should be fine. I should start asking around; networking is the only way I'm going to find the necessary experts.

Coursework. Before setting out on a quest, there are a lot of things to learn. The team needs to know where they are going, select the tools they will use, and have an idea about whom they will meet on the road and how these creatures should be handled. Most of our participants were in agreement that a lot of what they learned in the courses of their home discipline (Hobbiton) was useful if they wanted to stay and work in that discipline for the rest of their lives. However, coursework from Hobbiton was not always applicable to an ID quest. All participants mentioned that the most useful information was obtained through independent reading. Many described at least one fruitful learning experience, often informal, with students or faculty members from another discipline, similar to the valuable knowledge Bilbo and the dwarves gained while spending time with the elves in Rivendell. Unfortunately, our respondents noted difficulty in receiving credit for coursework outside of Hobbiton, a fact that many found discouraging.

Working with a committee. Students were eager to talk about their experiences of working with their supervisory committee. For most students, as for Bilbo, this was an ID committee with theoretical and methodological alliances and conflicts, and with members who tried to steer the student in particular directions. Some found working with a committee was like being pulled in two separate directions while trying to convince each member that it was possible to work in the middle, or do both tasks. As Bilbo might articulate: "Balin, I understand why you think I should focus more on getting the treasure, and Elrond, I understand the importance of slaying the dragon. I really think I can do both, so why do I have to choose one or the other? Neither aspect is more important to me." Others students were less willing to compromise, and in some cases, they altered the composition of the committee to form a more harmonious group: "Balin, I know you're the only one who has been to the mountain before, but if you can't get behind my proposed route, I'm going to have to relieve you of your committee duties. Thorin, Gandalf, and Elrond will ably fill your shoes."

Most students told a story that reflected that their first priority was trying to keep the committee members happy so the project could progress. Students described themselves as acting as go-betweens, connecting different committee members and wanting the committee members to talk to each other rather than expressing their views solely to the student:

This negotiation is more difficult because we haven't had the chance to sit down as a group. Let's look at the areas of congruence and conflict. I'll act as a bridge and try to negotiate a way to work between your priorities and construct a project that everyone is happy with. I do appreciate your different perspectives and the different types of knowledge you bring.

Refining the quest. As the journey progresses, and the question and aim are refined, it is important for the student and committee to clearly articulate the goal and consider the plan for achieving that goal. When talking about the process of refining the research question and approach, some students expressed frustration at the different per- 
spectives of the committee members. The conflict was slowing the project down, leaving students thinking: "Who cares whether the dwarves are happy? This is my quest and I'm going to do it my way. They should stop squabbling. It's really just slowing me down. They clearly don't understand interdisciplinary questing." Others took a different view of this intra-committee conflict, seeing it as an important and essential element of the research process: "I'm doing a lot of work to adjust the elements of the quest to satisfy all of the different people involved - but this is actually the most important part of the quest. I'm gaining a deeper understanding of dwarf culture, and how dwarves relate socially and historically to the elves and goblins."

By far the majority of participants described an appreciation for different perspectives on the committee and a commitment to designing a project that satisfied all members. These students often commented that this process was frustrating but worthwhile, as it strengthened the project. Students who encountered significant conflict within their committee remarked on the importance of flexibility and a commitment to interdisciplinary learning among committee members who choose to participate in interdisciplinary research:

Everyone has different priorities, and it's difficult to include each element the committee thinks is important. A lot of work is involved to make sure that everyone is satisfied and the core of the quest is still present. The quest has changed significantly from what I first thought I would be doing, but now I think it is much stronger and more achievable. A committee with a willingness to work in an interdisciplinary way is essential to refining the quest.

Colleagues. Every participating student had graduate student and faculty colleagues in their home discipline with whom they discussed their research in formal or informal settings. As in The Hobbit, disciplinary colleagues can be a great resource. They can support each other intellectually and emotionally. They can share resources and help each other avoid traps and unsavory creatures. However, a colleague's opinion of the quest and his or her own questing abilities might restrict this kind of camaraderie.

For example, a small number of participants expressed having unpleasant experiences when talking about their interdisciplinary research with colleagues working on disciplinary projects, lamenting: "Most of the hobbits in Hobbiton think I'm nuts! They work exclusively in Hobbiton and don't understand why I want to go somewhere else. Some of them have said some rude and discouraging things about my quest." Other students, who had met colleagues from other disciplines working in the same area, described these conversations as particularly enriching: "I have met a few elves and humans who have gone on similar quests, and it was great to trade stories with them. I had to look pretty hard to find this community, though."

The dominant narrative on this topic was one of intellectual isolation but social acceptance, where camaraderie was found with fellow graduate students, some of whom might even have been doing interdisciplinary projects themselves. Unfortunately, these relationships did not extend to significant discussions of the respondents' own research, and the students sometimes felt there was no one who could understand the whole scope of their project. "I know other hobbits who have been on quests, but the differences in our respective quests are so significant that we don't have much in common. While it's nice to talk with others who've been on quests, it's not the same as talking to someone who has traveled to the Lonely Mountain in search of Smaug." 
Working with the committee. As the research process continues, there are many decisions to be made along the way. Ideally, the committee will help the student avoid dangerous areas and guide him or her to safe and productive areas. Alternatively, conflict within the committee might stop the project from progressing at all. A sizeable minority of participants commented that conflict throughout the research process was minimal; after the project aim and methodologies were established, committee members tended to comment only on their areas of expertise. These students expressed trepidation that no one was commenting on the congruency of the whole project. "There's rarely any conflict at all between committee members. Everyone only comments on his own area of expertise. For example, the dwarves know a lot about treasure, so they talk about that and never comment on dragon slaying. It leaves me worrying that I might be missing something, though." A very small minority of students commented that the committee was really keen to work in an interdisciplinary way, meeting regularly as a group to read and learn and progress together. Most participants found that it was difficult to proceed in a way that was acceptable to everyone, and conflict continued past the initial establishment of the research project, rendering compromise and negotiation necessary at each step along the way: "Each committee member thinks I should take the trails they know, use the maps they've used. They don't understand why I have to do it my way, or the value of using someone else's conflicting expertise."

The joys and struggles of questing. When students commented on what had gone well throughout their research project, they mentioned an excitement and commitment to the topic, and an enjoyment of scholarly networks and interdisciplinary connections:

The excitement and enthusiasm for the quest keeps me going through the tough spots. I've enjoyed meeting and working with wizards, trolls, dwarves, and humans. I learned a lot from each of them and believe that we have more in common than most people think we do. I've enjoyed the fact that there are no boundaries.

Students had a lot to say when asked what challenges they had faced along their doctoral journey, and there were many common themes:

I have done more work to finish my quest than anyone else I know has had to do. It's been really hard to keep my committee together and satisfied with the work I'm doing. They're not committed to working together. They just want me to do it their way. My quest has taken longer as a result of that challenge. This quest has been lonely and frustrating. I have often thought of abandoning my quest altogether or just going back to Hobbiton and trying something like everyone else there is doing, because that seems easier.

Plans for the future. Despite the many challenges described, most students were optimistic about their future as scholars, seeing their interdisciplinary work as creating a unique niche, producing knowledge that was novel, valuable, and applicable to real-world problems. "If I succeed at this quest, I will have many opportunities ahead of me. My quest is unique. No one else does anything like this. My work will be applicable to the real world. It will help other people form policy and contribute to industry. I will be a bridge builder." 


\section{Discussion}

Over the course of this research, our team has learned a great deal in the process of listening to and creating stories of ID experiences with our participants. A sense of community is created when researchers and participants have an opportunity to come together and discuss emerging themes, which, according to Creswell (2008), "may make them feel that their stories are important and that they are heard" (p. 511). In this study, we were drawn in by what the narrators were feeling as they talked about their experiences working in ID contexts. Their stories were compelling and may be useful in raising awareness of the issues with other students, faculty, and administrators seeking to better support this unique way of working together. The stories reflect both the complexity and the contradiction (Clandinin \& Connelly, 2000, p. 181) inherent in ID doctoral supervision.

While our decision to employ critical narrative methods allowed us to represent a significant portion of the data, there were some gaps in the metaphor that did not adequately reflect some of the less prevalent stories that we heard. For example, as none of our doctoral students had defended their dissertations yet, they were not able to experientially characterize examiners as friendly, helpful beings, interested in trying to assist the candidate with strengthening his or her work or furthering the research agenda. Similarly, there was a sense in which the metaphor presented knowledge as a treasure to be acquired ("transferred" or "stolen"), as an end product, rather than there being value in the knowledge-seeking process itself. The narrative represents the doctoral journey only as a harrowing experience. While this was reflected in the data, it may have indicated their progress through the doctoral journey to date. While we reported the overarching themes and counter-narratives, this process did not account for nuanced differences in supervisory relationships between, for example, female-female, female-male, and malemale combinations. We were aware of circumstances in which a supervisor had done considerable work to smooth tensions behind the scenes, purposely keeping this intervention invisible to the student so that it not distract from his or her work. It seemed that in this research, participants often described the supervisors in terms of their absence more than their presence, which was certainly more congruent with the characterization of a supervisor as Gandalf.

\section{Creating a Culture to Support ID Work}

The tensions and conflict articulated by the participants underscore the need to develop a culture that better supports ID work. This includes providing more opportunities for faculty and students to interact with each other outside of their home discipline. Given the encouragement from funding organizations to develop ID teams, forming a collaborative culture is an important first step to foster relationships and opportunities for individuals to learn about possible ways that their research interests might intersect. The development of such communities may depend upon engaging strategically in communication with administration and policy decision-makers to make the need for a collaborative culture visible.

The research also made it clear that mentoring and peer support for students and their supervisors may have reduced feelings of isolation or "being lost." Learning from others' experiences may have served to orient newcomers to the journey, provide some of the tools they would need along the way, and help them navigate unfamiliar territory. 
The power of metaphor and story in conveying seemingly invisible dimensions of human experience cannot be overstated (Lakoff \& Johnson, 1980). It is our hope that storying the quests of the interdisciplinary doctoral students in this study opens a dialogue about this topic, and contributes to a deeper understanding of the phenomenon of the quests in which interdisciplinary doctoral students find themselves. There is still a long way to go in mapping this terrain, but there is little doubt that more and more students will be embarking on interdisciplinary quests, so we hope that other researchers will join this "adventure series."

\section{Acknowledgements}

Thank you to our participants: the students, faculty, and administrators across the university who were willing to share their stories with us, despite the fact that these stories were in the midst of unfolding at the time of this study.

\section{References}

Aboelela, S. Larson, E., Bakken, S. Carrasquillo, O., Formicola, Al, Glied, S, Haas, J. \& Gebbie, K.M. (2006). Defining interdisciplinary research: Conclusions from a critical review of the literature. Health Services Research, 42(1), 329-346.

Australian Learning and Teaching Council. (2010). Building research supervision and training across Australian universities. Final report. Sydney: University of Technology, Sydney. Retrieved from http://www.olt.gov.au/project-building-research-supervisionuts-2007

Beddoes, K., Borrego, M., \& Jesiek, B. (2011). Using boundary negotiating artifacts to investigate interdisciplinary and multidisciplinary teams. Proceedings of the 2011 ASEE Annual Conference and Exposition. Vancouver, Canada, 26-29 June 2011. Retrieved from http://jee.asee.org/file_server/papers/attachment/file/ooo1/1461/BNA_3-11-11.pdf

Begg, M., \& Vaughn, R. (2012). Are biostatistics students prepared to succeed in the era of interdisciplinary science? (And how will we know?). The American Statistician, 65(2), 71-79.

Blackmore, K., \& Nesbitt, K. (2008). Identifying risks for cross-disciplinary higher degree research students. Proceedings of the Tenth Conference on Australasian Computing Education, 78, 43-52.

Boden,D.,Borrego,M.,\&Newswander,L.(2011).Studentsocializationininterdisciplinary doctoral education. Higher Education, 62, 741-755.

Boix Mansilla, V., \& Duraising, E. D. (2007). Targeted assessment of students' interdisciplinary work: An empirically grounded framework proposed. The Journal of Higher Education, 78(2), 215-237.

Britzman, D. P. (1991). Practice makes practice. Albany, NY: State University of New York Press.

Bruner, J. (1996). The culture of education. Cambridge, MA: Harvard University Press.

Choose Your Own Adventure ${ }^{\circledR}$. (2012). Home page. Retrieved from http://www.cyoa.com 
Clandinin, D. J., \& Connelly, F. M. (2000). Narrative inquiry: Experience and story in qualitative research. San Francisco, CA: Jossey-Bass.

Clandinin, D. J., \& Rosiek, J. (2007). Mapping a landscape of narrative inquiry: Borderland spaces and tensions. In D. J. Clandinin (Ed.), Handbook of narrative inquiry (pp. 35-76). Thousand Oaks, CA: Sage.

Creswell, J. W. (2008). Educational research: Planning, conducting and evaluating quantitative and qualitative research (3rd ed.). Upper Saddle River, NJ: Pearson Education.

Davies, M., \& Devlin, M. (2010). Interdisciplinary higher education. In M. Davies, M. Devlin, and M. Tight (Eds.), Interdisciplinary higher education: Perspectives and practicalities (pp. 3-28). London, UK: Emerald Group Publishing.

Denzin, N. K., \& Lincoln, Y. S. (2000). The discipline and practice of qualitative research. In N. K. Denzin \& Y. S. Lincoln (Eds.), Handbook of qualitative research (pp. 1-29). Thousand Oaks, CA: Sage Publications.

Denzin, N. (2001). Interpretive Interactionism. Sage Publications

Deuchar, R. (2008). Facilitator, director or critical friend? Contradiction and congruence in doctoral supervision styles. Teaching in Higher Education, 13(4), 489-500.

Franke, A., \& Arvidsson, B. (2011). Research supervisors' different ways of experiencing supervision of doctoral students. Studies in Higher Education, 36(1), 7-19.

Grant, B. M. (2003). Mapping the pleasures and risks of supervision. Discourse, 24(2), 175-190.

Grant, B. M. (2005). Fighting for space in supervision: Fantasies, fairytales, fictions and fallacies. International Journal of Qualitative Studies in Education, 18(3), 337-354.

Green, B. (2005). Unfinished business: subjectivity and supervision. Higher Education Research and Development, 24(2), 151-163.

Green, B., \& Lee, A. (1995). Theorising postgraduate pedagogy. Australian Universities' Review, 2(1), 41.

Grumet, M. (1988). Bitter milk. Amherst, MA: University of Massachusetts Press.

Hall, P., \& Weaver, L. (2001). Interdisciplinary education and teamwork: A long and winding road. Medical Education, 35(9), 867-875.

Halse, C., \& Malfroy, J. (2010). Re-theorizing doctoral supervision as professional work. Studies in Higher Education, 35(1), 79-92.

Holley, K. A. (2013). Doctoral education and the development of an interdisciplinary identity. Innovations in Education and Teaching International. Available from doi.org/ 10.1080/14703297.2013.847796.

Kiley, M. (2009). "You don't want a smart alec": Selecting examiners to assess doctoral dissertations. Studies in Higher Education, 34(8), 889-308.

Lakoff, G., \& Johnson, M. (1980). Metaphors we live by. Chicago, IL: University of Chicago Press. 
Lannamann, J. W., \& McNamee, S. (2011). Narratives of the interactive moment. Narrative Inquiry, 21(2), 382-390.

Lee, A. (2008). How are doctoral students supervised? Concepts of doctoral research supervision. Studies in Higher Education, 33(3), 267-281.

Lee, A., \& Green, B. (2009). Supervision as metaphor. Studies in Higher Education, 34(6), 615-630.

Lofstrom, E., \& Pyhalto, K. (2012). The supervisory relationship as an arena for ethical problem solving. Education Research International. Retrieved from http://dx.doi. org/10.1155/2012/961505

Lyall, C., \& Meagher, L. R. (2012). A masterclass in interdisciplinarity: Research into practice in training the next generation of interdisciplinary researchers. Futures, 44(6), 608-617.

Manathunga, C. (2007). Supervision as mentoring: The role of power and boundary crossing. Studies in Continuing Education, 29(2), 207-221.

Manathunga, C., Lant, P., \& Mellick, G. (2006). Imagining an interdisciplinary doctoral pedagogy. Teaching in Higher Education, 11(3), 365-379.

McCallin, A., \& Nayar, S. (2012). Postgraduate research supervision: A critical review of current practice. Teaching in Higher Education, 17(1), 63-74.

McCormack, C., \& Pamphilion, B. (2004). More than a confessional: Postmodern groupwork to support postgraduate supervisors' professional development. Innovations in Education and Teaching International, 41(1), 23-37.

McNair, L., Newswander, C., Boden, D., Borrego, M. (2011). Student and faculty interdisciplinary identities in self-managed teams. Journal of Engineering Education, $100(2), 374-96$.

McWilliam, E., \& Palmer, P. (1995). Teaching tech(no)bodies: Open learning and postgraduate pedagogy. Australian Universities' Review, 38(2), 32-34.

Millar, M. M., \& Dillman, D. A. (2010a). Analyses of interdisciplinary doctoral research data from the survey of earned doctorates. A report to the National Science Foundation Division of Science Resources Statistics. Pullman, WA: Washington State University.

Millar, M. M., \& Dillman, D. A. (2010b). Defining and identifying interdisciplinary research among doctoral candidates. A report to the National Science Foundation Division of Science Resources Statistics. Pullman, WA: Washington State University.

Miller, D. C., \& Salkind, N. J. (2002). Handbook of research design and social measurement ( $6^{\text {th }}$ ed.). Thousand Oaks, CA: Sage Publications.

Mishler, E. G. (1991). Research interviewing: Context and narrative. Cambridge, MA: Harvard University Press.

Mishler, E. G. (1995). Models of narrative analysis: A typology. Journal of Narrative and Life History, 5(2), 87-123. 
Nisselle, A., \& Duncan, R. (2008). Multiple supervisors from multiple disciplines: Lessons from the past as multidisciplinary supervision becomes the way of the future. Traffic (Parkville), 1O(1), 143.

Okri, B. (1995). Birds of heaven. London, UK: Orion Books.

Parchoma, G., \& Keefer, J. (2012). Contested disciplinarity in international doctoral supervision. In V. Hodgson, C. Jones, M. de Laat, D. McConnell, T. Ryberg, \& P. B. Sloep (Eds.), Proceedings of the 8th International Conference on Networked Learning (pp. 498-505). Heerlen, Netherlands: Open Universiteit Nederland.

Petersen, E. B. (2007). Negotiating academicity: Postgraduate research supervision as category boundary work. Studies in Higher Education, 32(4), 475-487.

Pinnegar, S., \& Daynes, J. (2007). Locating narrative inquiry historically. In J. D. Clandinin (Ed.), Handbook of narrative inquiry: Mapping a methodology (pp. 1-34). Thousands Oaks, CA: Sage Publications.

Rhoten, D. (2004). Interdisciplinary research: Trend or transition. Items \& Issues, $5(1-2), 6-11$.

Rhoten, D., \& Parker, A. (2004). Risks and rewards of an interdisciplinary research path. Science, 306(5704), 2046.

Richardson, L. (1997). Fields of play: Constructing an academic life. New Brunswick, NJ: Rutgers University Press.

Sá, C. M. (2006). Interdisciplinary strategies at research-intensive universities. Doctoral dissertation. Pennsylvania State University. Available from ProQuest Dissertations and Theses.

Sá, C. M. (2008a). "Interdisciplinary strategies” in U.S. research universities. Higher Education, 55(5), 537-552.

Sá, C. M. (2008b). Strategic faculty hiring in two public research universities: Pursuing interdisciplinary connections. Tertiary Education and Management, 14(4), 285-301.

Sambrook, S., Stewart, J., \& Roberts, C. (2008). Doctoral supervision: A view from above, below and the middle. Journal of Further and Higher Education, 32(1), 71-84.

Schmidt, A., Robbins, A., Combs, J., Freeburg, A., Jesperson, R., Rogers, H.,... Wheat, E. (2012). A new model for training graduate students to conduct interdisciplinary, interorganizational and international research. Bioscience, 62(3), 296-304.

Spector-Mersel, G. (2010). Narrative research: Time for a paradigm. Narrative Inquiry, 2O(1), 204-224.

Spelt, E., Biemans, H., Tobi, H., Luning, P., \& Mulder, M. (2009). Teaching and learning in interdisciplinary higher education: A systematic review. Educational Psychology Review, 21(4), 365-378.

Taylor, S., \& Beasley, N. (2005). A handbook for doctoral supervisors. New York: Routledge.

Tolkien, J. R. R. (1937). The Hobbit. Boston, MA: Houghton Mifflin. 
Trujillo, N. (1985). Organizational communication as cultural performance: Some managerial considerations. Southern Speech Communication Journal, 5o(3), 201-224.

Vanstone, M., Hibbert, K., Kinsella, E. A., McKenzie, P., Lingard, L., Pitman, A., \& Wilson, T. (2013). Interdisciplinary doctoral research supervision: A scoping review. Canadian Journal of Higher Education, 43(2), 42-67.

Walker, M., \& Thomson, P. (Eds.). (2010). The Routledge doctoral supervisor's companion: Supporting effective research in education and the social sciences. New York, NY: Routledge.

Wenger, E. (1998). Communities of practice: Learning, meaning, and identity. Cambridge, UK: Cambridge University Press.

Zhao, F. (2010). Transforming quality of research supervision: A knowledge management approach. Quality in Higher Education, 9(2), 187-197.

\section{Contact Information}

Kathryn Hibbert

Faculty of Education

Western University

khibbert@uwo.ca

Kathryn Hibbert is Associate Professor in the Faculty of Education, Centre Researcher in the Centre for Education Research and Innovation at the Schulich School of Medicine \& Dentistry, and founding Director of the Centre for Medical Imaging Education, Western University. Her program of research looks at how our abilities to read "texts" and use multimedia/other technologies shape our ability to communicate and learn. She leads a Narrative Mentoring Group for faculty and students across the university.

Lorelei Lingard is Professor in the Department of Medicine and Director of the Centre for Education Research \& Innovation at the Schulich School of Medicine \& Dentistry, Western University. As a rhetorician who works as a scientist of medical education, she lives in the land of interdisciplinarity. Her research program studies interprofessional healthcare teams in a variety of clinical settings, with particular attention to the role of language in collaborative work and in novice socialization. She mentors graduate students in the art and science of conducting interdisciplinary research, and has an interest in guiding faculty to effectively position their interdisciplinary work for maximal effect in the academic economy of the university.

Meredith Vanstone is an Assistant Professor in the Department of Clinical Epidemiology and Biostatistics and a member of the Centre for Health Economics and Policy Analysis at McMaster University. She has experience on both sides of the interdisciplinary graduate research relationship. At the time this study was conducted, she was a student in an interdisciplinary doctoral program (Health Professional Education). As a faculty member, she teaches and supervises in three interdisciplinary graduate programs (Health Policy, Health Sciences Education, Health Research Methodology). Her research focuses on social and ethical dimensions of health policy, health technology assessment, and health 
professional education.

Elizabeth Anne Kinsella is an Associate Professor in the Faculty of Health Sciences at Western University. She is the field leader of an interdisciplinary graduate program in Health Professional Education, past director of INSPiRE - the Interdisciplinary Network for Scholarship in Professions' Research in Education, at Western University - and an adjunct professor with the Australian Research Institute for Professional Practice, Learning and Education at Charles Sturt University. Dr. Kinsella is engaged in interdisciplinary theoretical and empirical work that contributes to understanding reflection, reflective practice, reflexivity, and dialogue as they relate to knowledge generation in the health professions.

Pam McKenzie is Associate Professor and Associate Dean in the Faculty of Information and Media Studies at Western University. Her research sits at the intersection of library and information studies, communication, sociology, health studies, gender studies, family studies, and organizational studies. She has served on supervisory committees and examined theses in library and information science, health and rehabilitation sciences, health communication, nursing, women's studies and feminist research, education, media, communication and cultural studies, history, and business.

Allan Pitman is an Associate Professor at the Faculty of Education and Director of INSPiRE - the Interdisciplinary Network for Scholarship in Professions' Research in Education, at Western University. His research examines the relationship between curriculum policy and teachers' work. He recently co-edited the book Phronesis as Professional Knowledge: Practical Wisdom in the Professions, published by Sense.

Tim D. Wilson is an Associate Professor in the Department of Anatomy and Cell Biology, Schulich School of Medicine and Dentistry, at Western University. He is steeped in interdisciplinary training and practice, which has formed his philosophy on teaching, supervision, and mentorship. As faculty, he teaches at all levels: graduate, undergraduate, and professional students in wide-ranging, yet health-related, fields of study. His research foci explore educational scholarship in digital learning object creation and the resulting impact these tools may have on students. 